\title{
O Naturalismo Biológico de Searle e a Relação Mente-cérebro
}

\author{
Carlos Eduardo de Sousa Lyra ${ }^{1}$ \\ Universidade Estadual do Piauí \\ Gabriel José Corrêa Mograbi \\ Universidade Federal de Mato Grosso \\ Charbel Niño El-Hani \\ Universidade Federal da Bahia
}

\begin{abstract}
RESUMO - Apresentamos o ‘naturalismo biológico’ de John Searle enquanto possível referencial filosófico para um estudo da mente em diálogo com a neurociência contemporânea. O método utilizado baseia-se em uma revisão crítica e sistemática das principais obras de John Searle sobre a consciência e o problema mente-corpo, com eventuais consultas a outros autores. Nosso objetivo principal é demonstrar que a resolução apresentada por Searle ao problema mente-corpo acaba por introduzir um dualismo de propriedades ou de perspectivas que não resolve, de fato, o problema. Apesar disso, reconhecemos a posição apresentada por Searle como um avanço importante na tentativa de enfrentar a tradição cartesiana e alguns de seus caudatários contemporâneos.
\end{abstract}

Palavras-chave: naturalismo biológico, filosofia da mente, neurociência, consciência, mente e corpo, dualismo

\section{Searle's Biological Naturalism and the Mind-Brain Relationship}

\begin{abstract}
In this paper we present John Searle's 'biological naturalism' as a possible philosophical reference for a study of the mind in dialogue with contemporary neuroscience. The method used in the present study is based on a critical and systematic review of John Searle's major works on consciousness and the mind-body problem, with occasional recourse to other authors. Our main goal is to show, though the analysis of arguments and original citations, that Searle's alleged resolution to the mind-body problem introduces a kind of property dualism or perspectival dualism, which in fact does not solve that problem. Notwithstanding, we recognize that Searle's account presents an important advance in the attempt to challenge the Cartesian tradition and some of its contemporary advocates.
\end{abstract}

Keywords: biological naturalism, philosophy of mind, neuroscience, consciousness, mind and body, dualism

A posição defendida pelo filósofo John Searle (1992/2006) em relação ao problema mente-corpo e à questão da consciência é conhecida, em filosofia da mente, como "naturalismo biológico". Uma das formulações mais clássicas do "naturalismo biológico" se encontra na seguinte afirmação de Searle (1992/2006, p. 7): “Os processos e fatos mentais fazem parte de nossa história natural biológica tanto quanto a digestão, a mitose, a meiose ou a secreção enzimática". Nessa mesma página, o autor afirma que uma solução para o problema mente-corpo que superasse os problemas da tradição dualista filosófica implicaria assumir que "os fenômenos mentais são causados por processos neurofisiológicos no cérebro, e são, eles próprios, características do cérebro" (Searle, 1992/2006, p. 7). Com isso, Searle está afirmando (a) que microprocessos neurobiológicos, que ocorrem no cérebro - ao nível dos neurônios e das sinapses -, causam a consciência e outros estados mentais e (b) que estes são características de nível superior do próprio cérebro (Searle, 1984/2000a, 1992/2006, 1997/1998, 2000b, 2002/2010). Vale notar, ainda, que, ao referir-se aos fenômenos mentais, Searle inclui tanto aqueles que são conscientes como os inconscientes.

De acordo com Searle (1992/2006), qualquer investigação a respeito da mente deve incluir necessariamente o estudo da consciência, cuja principal característica é a de ser subjetiva,

1 Endereço para correspondência: Rua Raimundo Diógenes da Silveira, 750, Santa Fé, São Raimundo Nonato, PI, Brasil. CEP: 64.770-000. E-mail: ceslyra@hotmail.com isto é, sempre se apresentar na perspectiva de primeira pessoa. Em outras palavras, ele afirma que a ontologia do mental é, em sua essência, uma ontologia de primeira pessoa. Entretanto, é preciso entender algumas visões gerais defendidas por Searle para que se possa compreender o que seja essa ontologia de primeira pessoa e suas implicações. Vejamos primeiro como Searle (1992/2006) diferencia, em termos mais gerais, o que seria ontologia, epistemologia e causação:

Há uma distinção entre as respostas às questões: $O$ que é isto? (ontologia), Como tomamos conhecimento disto? (epistemologia), e O que isto causa? (causação). Por exemplo, no caso do coração, a ontologia é que este é uma grande peça de tecido muscular na cavidade torácica; a epistemologia é que descobrimos isto através do uso de estetoscópios, eletrocardiogramas e, numa emergência, podemos abrir o peito e dar uma olhada; e a causação é que o coração bombeia sangue através do corpo. Com essas distinções em mente, podemos começar o trabalho. (p. 31)

No capítulo 5 de sua obra A Redescoberta da Mente, intitulado "Reducionismo e a irredutibilidade da consciência", Searle (1992/2006) mostra que a diferenciação entre ontologia e epistemologia que se aplica à quase totalidade dos fenômenos naturais não poderia ser transplantada para o estudo da consciência, e termina por colapsar aquela diferenciação no que concerne a esse fenômeno sui generis:

Aprendemos sobre calor ou luz através da sensação ou da visão, mas então definimos o fenômeno de uma maneira que é 
independente da epistemologia. A consciência é uma exceção a este modelo por uma razão trivial. O motivo, repetindo, é que as reduções que deixam de lado as bases epistêmicas, as aparências, não podem funcionar no caso das próprias bases epistêmicas. Em tais casos, a aparência é a realidade. (p. 177)

Portanto, ao defender o papel fundamental da consciência e da perspectiva de primeira pessoa no estudo da mente, Searle (1992/2006) acaba por realizar uma crítica severa principalmente aos behavioristas - que costumam reduzir os estados mentais a observações objetivas acerca do comportamento (behaviorismo metodológico ou radical) ou a disposições para comportamento (behaviorismo lógico ou analítico) - e aos funcionalistas - que definem os estados mentais em termos de suas relações causais, tendo por modelo os programas computacionais produzidos pela Inteligência Artificial. Segundo Searle, ambos trabalham apenas com a perspectiva de terceira pessoa, excluindo qualquer referência à subjetividade, o que implica perder de vista, pois, aquela que seria a principal característica da consciência.

Nosso objetivo principal, neste artigo, é discutir a resolução que Searle acredita dar ao problema mente-corpo. Como veremos, ele acaba por introduzir uma espécie de dualismo de propriedades ou dualismo de perspectivas que não resolve, em nosso entendimento, o problema. Apesar disso, reconhecemos a posição apresentada por Searle como um avanço importante na tentativa de enfrentar a tradição cartesiana e alguns de seus caudatários contemporâneos.

\section{O Dualismo Cartesiano e sua Influência sobre o Materialismo Científico}

Como muitos outros autores, Searle (1992/2006) toma como contraponto de seus argumentos a introdução por René Descartes (1641/2004) do dualismo mente-corpo na filosofia e na ciência moderna. Como é bem sabido, trata-se de afirmar a existência de duas substâncias distintas: a res cogitans (substância pensante ou "mente") e a res extensa (substância extensa ou "matéria"). Assim, tendo como uma de suas principais referências o dualismo cartesiano e levando em conta a sua própria constituição como modo de produção do conhecimento (pelas mãos de filósofos da natureza como Galileu, Newton e muitos outros), a partir do século XVII, a ciência passou a se ocupar apenas daquilo que podia ser testado empiricamente, observado objetivamente e medido quantitativamente, o que excluiu qualquer referência à consciência e ao sujeito. Segundo Searle (1992/2006), "a separação entre mente e matéria foi uma ferramenta heurística útil no século XVII, uma ferramenta que facilitou muito do progresso que ocorreu nas ciências" (pp. 126-127). Contudo, para esse filósofo, tal separação se tornou um obstáculo ao avanço da ciência contemporânea, se considerarmos que, neste momento, há pesquisadores - tanto no campo da filosofia das ciências e da mente, como em áreas como as ciências cognitivas e a neurociência - que se propõem a compreender o papel fundamental da consciência no mundo físico. Nesse sentido, Searle (1992/2006) pretende "remover esse obstáculo, trazer a consciência de volta ao objeto da ciência como um fenômeno biológico semelhante a qualquer outro" (p. 127). Para tanto, empreende uma dura crítica ao dualismo cartesiano, tal como usualmente interpretado, mostrando sua influência direta sobre toda a posterior tradição materialista na ciência.

Searle (1992/2006) afirma que não faz sentido realizarmos um estudo da mente sem investigarmos o papel desempenhado pela consciência. Para ele, a consciência é realmente a noção central quando se trata de compreender a mente, porque "todas as outras noções mentais - como intencionalidade, subjetividade, causação mental, inteligência etc. - só podem ser plenamente compreendidas como mentais por meio de suas relações com a consciência" (Searle, 1992/2006, pp. 125-126, ênfase no original). Assim, é preciso inserir a consciência em uma explicação científica mais geral a respeito do mundo físico, pelo menos no que concerne a um estudo da mente. Nesse sentido, Searle está de acordo com a necessidade de formular uma teoria neurobiológica da consciência que seja consistente com os pressupostos da física e da evolução, tendo em vista que sua visão científica do mundo inclui todas as teorias produzidas e justificadas no âmbito da ciência, desde as explicações da física sobre a origem do universo até as explicações evolucionistas acerca da origem da espécie humana e dos demais animais. Essa mesma visão é defendida por outros estudiosos da consciência, a exemplo do neurocientista Gerald Edelman (2006).

Searle (1992/2006) defende que não podemos considerar toda a realidade como sendo objetiva, porque parte dela é subjetiva. Nesse sentido, ele afirma que há entidades na natureza (como montanhas, oceanos, átomos etc.) que são ontologicamente objetivas, isto é, sua existência no mundo independe do fato de serem experimentadas por sujeitos humanos ou animais. Por outro lado, Searle defende que há fenômenos cuja existência depende da experiência subjetiva, como é o caso da consciência. Assim, ele sustenta a ideia de que a ontologia dos estados mentais é irredutivelmente subjetiva:

podemos resumir esta questão dizendo que a consciência não é redutível da maneira que outros fenômenos são redutíveis, não porque o modelo de fatos no mundo real envolva algo de especial, mas porque a redução de outros fenômenos depende em parte da distinção entre "realidade física objetiva", de um lado, e meras "aparências subjetivas", de outro; e da eliminação da aparência dos fenômenos que foram reduzidos. Mas no caso da consciência, sua realidade é a aparência. (Searle 1992/2006, p. 176)

Quando Searle (1992/2006) afirma, por exemplo, que "a consciência é uma propriedade causalmente emergente do comportamento de neurônios, e, portanto, a consciência é causalmente redutível aos processos do cérebro" (p. 168), isso não consiste, para ele, numa redução ontológica, mas numa redução causal. Esta espécie de redução está relacionada à dimensão epistêmica da distinção objetivo/ subjetivo. De acordo com tal distinção, a ciência pode ter acesso aos fenômenos naturais (sejam esses ontologicamente objetivos ou subjetivos) através de métodos objetivos, testando as hipóteses e teorias científicas com base em dados empíricos, independentemente das preferências pessoais ou dos preconceitos e das atitudes de cada cientista. Portanto, se a ontologia do mental é sempre uma ontologia de primeira pessoa, mesmo que tenhamos uma teoria neurobiológica da 
consciência que seja capaz de fornecer explicações causais para os fenômenos mentais utilizando métodos objetivos (redução causal), ainda assim, aspectos como a subjetividade, a qualidade e a unidade continuarão a caracterizar, para Searle, a ontologia dos estados mentais. Ainda segundo Searle (1992/2006), a realidade da consciência é a aparência:

Na verdade, é uma característica geral de tais reduções que o fenômeno seja definido em termos da "realidade" e não em termos da "aparência". Mas não podemos fazer este tipo de distinção aparência-realidade para a consciência, porque a consciência consiste nas próprias aparências. Onde a aparência está envolvida, não podemos fazer a distinção aparência-realidade porque a aparência é a realidade. (p. 176, ênfase no original)

Nesse sentido, Searle afirma que isso não implica que a consciência não seja parte do aparato da realidade (p. 177), ou que o fato de ela ser subjetiva gere consequências científicas impróprias (p.179), ou mesmo, que a consciência não possa, $a$ priori, ser reduzida em uma revolução intelectual atualmente inimaginável (p. 179). O que ele afirma é a irredutibilidade da consciência nos atuais modelos padrões de redução (p. 179).

Ao defender a irredutibilidade ontológica dos estados mentais, Searle (1992/2006) afirma que não está assumindo nem uma posição dualista cartesiana, nem uma posição materialista reducionista. Ao mesmo tempo, ele também não pretende excluir a consciência de uma visão científica mais geral sobre o mundo, como propõem, por exemplo, os materialistas eliminativistas. Como discute Maslin (2007/2009), Searle está comprometido com o materialismo não-redutivo, defendendo que propriedades mentais, como consciência e intencionalidade, são ontologicamente distintas de propriedades físicas como o calor. Isso porque não podem ser redutíveis ontologicamente ao comportamento de microelementos puramente físicos. Tal posição adotada por Searle permite que muitos filósofos, a exemplo de Patrícia Churchland (1997), classifiquem-no como um "dualista de propriedades", embora o próprio Searle (1992/2006, 1997/1998, 2002/2010) negue de modo recorrente esse rótulo. Tal crítica é justamente devida ao fato de que a consciência em Searle está marcada por esse colapso entre ontologia e epistemologia, sendo o único fenômeno por ele apontado a ter uma propriedade irredutível ao físico, justamente aquela de não permitir distinção entre aparência e realidade. Além disso, Searle não tem um modelo claro de emergência. No capítulo 5 de A Redescoberta da Mente, no qual tal tema é abordado, Searle (1992/2006) trabalha com duas noções de emergência, ainda que não apresente um modelo formal ou matemático. A primeira, mais sóbria, caracteriza a consciência como causalmente redutível: uma propriedade emergente seria uma propriedade de sistemas explicada pela interação causal de seus elementos. A segunda afirma que uma propriedade é emergente, se e somente se, seus poderes causais não podem ser explicados pelas interações causais das partes. Searle afirma que não aceita a segunda visão e endossa a primeira.

Searle (1992/2006) considera que, se entendermos a ontologia do mental como uma ontologia de primeira pessoa, qualquer tentativa de reduzir o mental ao estudo do comportamento objetivamente observável não contemplaria a principal característica do mental, que é a subjetividade.
Isso não implica que devamos abandonar o estudo do comportamento em termos do que pode ser observado objetivamente por uma terceira pessoa. Contudo, devemos, sempre que possível, buscar o relato subjetivo, em primeira pessoa, para poder realizar um estudo coerente com a própria natureza do mental. Não podemos utilizar apenas uma metodologia de terceira pessoa para estudar os fenômenos mentais simplesmente porque corremos o risco de submeter a realidade subjetiva do mental a uma redução ontológica (e não somente a uma redução causal).

De fato, é possível conhecer o funcionamento do cérebro através de métodos objetivos. Isso é o que a neurociência se propõe a fazer. Mais do que isso: existem aqueles que consideram ser possível fornecer uma explicação do comportamento em termos de uma redução causal às relações entre neurônios individuais, como defende Francis Crick (1994), ou às relações entre grupos neuronais e destes com o corpo e com o meio ambiente, como propõe Gerald Edelman (1992/1998, 2006). Contudo, segundo Searle (1997/1998), tais explicações por si mesmas não contemplam a principal característica dos estados mentais, que reside no fato de serem subjetivos.

Searle (1992/2006) também defende que a relação entre comportamento e estados mentais é contingente, uma vez que é possível ter estados mentais sem que haja a manifestação de um comportamento (por exemplo, quando sonhamos). Para Searle (1992/2006), "no que diz respeito à ontologia da mente, o comportamento é irrelevante" (p. 115), o que não quer dizer que o comportamento não seja um objeto relevante de estudo, mas que, quando falamos da existência de estados mentais enquanto tais, pouco importa que sejam acompanhados de um comportamento. Em outras palavras, para Searle, a ocorrência de um comportamento correlativo a um estado mental não é nem necessário nem suficiente para a existência deste.

O estudo da consciência deve reconhecer, segundo Searle (1992/2006), que ela é uma propriedade do cérebro que é ontologicamente irredutível, dada a caracteristica de a subjetividade implicar uma ontologia de primeira pessoa. Dessa forma, é importante esclarecer como esse filósofo entende a consciência como característica biológica do cérebro.

\section{A Consciência como Característica Biológica do Cérebro}

Para compreender a espécie humana, é necessário incluir o estudo da consciência enquanto um fenômeno que surgiu ao longo da evolução das espécies animais, possuindo um papel adaptativo e causalmente eficaz no modo de existência daquela espécie em sua relação com o mundo. Ao aceitar uma visão de mundo científica, Searle (1992/2006) trata a consciência como uma característica biológica dos cérebros de seres humanos e determinados animais, como mencionamos anteriormente.

Uma vez que aceitemos este modo de compreender a consciência, parecerá então natural aceitarmos também que podemos investigá-la a partir da neurobiologia. Contudo, é preciso lembrar que, por muito tempo, houve resistência, 
tanto da parte dos neurocientistas como da parte de filósofos, psicólogos e cientistas cognitivos, em admitir a consciência como um objeto possível de estudo propriamente científico. Nesse sentido, foram raros os estudos que consideraram detidamente a contribuição das ciências para a investigação sobre a consciência, entre os quais podemos destacar os trabalhos de Wilhelm Wundt (Araújo, 2010), William James (1890/2010) e Sigmund Freud (1950/1990, 1900/2001, 1915/2006, 1940/1990), que são anteriores ao advento da neurociência contemporânea.

Entretanto, com o avanço dos métodos de pesquisa em neurociência, nos últimos anos, tornou-se mais acessível realizar uma investigação científica da consciência, de tal maneira que alguns neurocientistas contemporâneos, como António Damásio (1999/2000, 2010) e Gerald Edelman (1992/1998, 2006), engajados na tarefa de conceber uma teoria neurobiológica da consciência, passaram a dispor de melhores condições para realizar esse trabalho. Contudo, ainda há muitos dilemas importantes nessa área, como atestam os calorosos debates acerca das confusões conceituais presentes nas explicações de alguns cientistas e filósofos. Uma das principais confusões conceituais envolve o que Bennet e Hacker (2008) chamam de falácia mereológica, isto é, a ideia, comumente difundida entre os neurocientistas, de que o cérebro pensa, sente, decide etc. Assim como aqueles autores, acreditamos que não se pode atribuir capacidades individuais a um órgão do corpo que é somente uma parte de um indivíduo, mesmo que, do ponto de vista neurobiológico, tal órgão desempenhe um papel importante na ocorrência daquelas capacidades, como é o caso do cérebro humano.

$\mathrm{Na}$ medida em que a consciência deixou de ser apenas uma questão filosófica para tornar-se também um problema científico e, mais especificamente, neurobiológico (Searle, 2002/2010, 2004/2007), algumas questões passaram a ser relevantes para seu estudo, como, por exemplo: Como processos biológicos objetivos, que podem ser observados da perspectiva de terceira pessoa, também podem produzir sentimentos e pensamentos subjetivos, que, por sua vez, são experimentados pela primeira pessoa? Uma questão como essa deixou de ser do domínio exclusivo da filosofia para tornar-se também uma das questões cruciais em muitos dos atuais programas de pesquisa em neurociências. Contudo, por mais que a consciência se apresente na atualidade também como um problema biológico, isso não quer dizer que questões filosóficas não permaneçam profundamente relacionadas ao seu estudo. É nesse sentido que a filosofia de Searle tem desempenhado um importante papel nos debates atuais sobre o estudo da consciência.

\section{Características Estruturais da Consciência}

Ao termo consciência é comumente atribuída uma diversidade de sentidos, como sugerido pelo uso de termos como conscienciosidade, autoconsciência e cognição, postos em relação com consciência (Searle, 1992/2006). Esses sentidos não são considerados por Searle, no entanto, em sua tentativa de apresentar uma definição clara e precisa do que entende por consciência. Para além da compreensão da consciência enquanto característica biológica do cérebro, com todas as suas implicações, Searle também realiza uma abordagem propriamente filosófica do conceito. Para ele, "a consciência consiste em estados e processos de sensibilidade ou ciência, internos, qualitativos e subjetivos" (Searle, 2000b, p. 55; tradução nossa), e é sempre percebida como uma unidade e relatada em primeira pessoa. Assim, desde a hora em que acordo pela manhã até o momento em que adormeço à noite, vivencio uma série de experiências que me remetem ao estado de consciência: percebo os raios solares entrando pela janela, preparo o café da manhã, conduzo o meu veículo até o trabalho, converso com meus colegas sobre o resultado do jogo de ontem, sinto cansaço ao final do dia etc. Todas essas experiências são vivenciadas como sendo conscientes e são relatadas sempre na perspectiva de primeira pessoa. Outras experiências vivenciadas em primeira pessoa, como os sonhos, por exemplo, embora possam envolver formas de consciência, não são conscientes da mesma maneira que aqueles estados que posso vivenciar enquanto estou acordado. Searle (2000b) apresenta as seguintes características estruturais como sendo essenciais para um estudo científico da consciência: a qualidade, a subjetividade e a unidade.

A qualidade é uma característica presente em todo estado de consciência. Ela pode ser melhor compreendida quando a ilustramos com alguns exemplos: a experiência de ouvir o álbum The Dark Side of The Moon, do Pink Floyd, é bem diferente da experiência de degustar um delicioso mousse de chocolate, embora ambos possam proporcionar um imenso prazer. Outra forma de entender o aspecto qualitativo da consciência seria imaginar a experiência de ser um elefante, por exemplo. Certamente, é possível imaginar que a experiência de ser um animal como o elefante deve ter um aspecto qualitativo singular. Em filosofia da mente, esse aspecto qualitativo da consciência tem sido usualmente referido como qualia. No entanto, Searle prefere não utilizar esse termo, uma vez que isso poderia nos levar a pensar que existem dois problemas diferentes: o da consciência e o dos qualia. Para Searle (2000b), consciência e qualia são coextensivos, isto é, ele entende que o termo qualia equivale à expressão estados conscientes. Searle (1992/2006) defende que a sensação subjetiva (subjective feeling) é uma característica intrínseca da consciência. Para ele, não se pode superar a subjetividade do aspecto sensitivo dos estados conscientes: "Basta dizer que a subjetividade necessariamente envolve o aspecto sentir-se-como de estados conscientes" (Searle, 1992/2006, p. 190).

Ligada à questão da qualidade, portanto, a subjetividade é também uma característica própria dos estados conscientes. Em outras palavras, podemos dizer que toda experiência consciente é sempre vivenciada por um indivíduo (seja ele um ser humano ou algum outro animal ao qual atribuamos consciência, a exemplo de um chimpanzé ou um orangotango) dotado de uma subjetividade. Nesse sentido, a presença de uma determinada qualidade nos estados de consciência implica necessariamente a existência de uma subjetividade. Portanto, podemos dizer que não há experiência sem que haja uma subjetividade (Searle, 2000b). A existência de estados mentais conscientes, subjetivos, dotados de uma determinada qualidade, implica também a existência de uma ontologia de primeira pessoa (Searle, 1992/2006, 2000b), como já havíamos ressaltado no início deste trabalho. 
A unidade é também uma das três características essenciais da consciência, segundo Searle (2000b). Nesse sentido, podemos dizer que toda experiência consciente é vivenciada como sendo parte de um campo consciente unificado. Assim, quando um jogador da seleção brasileira de futebol está se preparando para fazer um gol, ele não apenas conduz a bola, como também é capaz de visualizar a posição do goleiro adversário ou, ainda, de sentir o suor molhado na camisa amarela e o vento na superfície do seu corpo. Na verdade, ele percebe tudo isso como sendo parte de um mesmo campo consciente unificado, isto é, como uma experiência unificada. A unidade, por sua vez, já está implícita nos conceitos de qualidade e subjetividade (o que reforça o fato de que a distinção entre essas características é feita apenas para fins do argumento). Mesmo se imaginarmos o jogador de futebol vivenciando isoladamente cada aspecto da cena acima (por exemplo, o jogador visualizando a posição do goleiro adversário), teríamos de admitir que um aspecto isolado da cena teria, ele mesmo, uma determinada qualidade e seria percebido como uma unidade por uma subjetividade. Em outras palavras, cada aspecto isolado da cena também se constitui em uma experiência consciente subjetiva, dotada de uma determinada qualidade e unidade ${ }^{1}$.

Até o momento, destacamos a importância das três características essenciais dos estados de consciência. Contudo, Searle (2000b) também menciona outras características presentes nos estados de consciência, quais sejam: a intencionalidade; a distinção entre centro e periferia da atenção; o estado de humor; a dimensão prazer/desprazer; a estrutura gestáltica; e a familiaridade.

A intencionalidade é uma importante característica atribuída aos estados de consciência. Trata-se da propriedade que os estados mentais têm de ser acerca de alguma coisa, isto é, de se referir aos objetos que fazem parte do mundo. Assim, a intencionalidade é um atributo de nossas crenças, desejos, intenções, medos etc., ou seja, de qualquer estado mental passível de expressão numa proposição que tenha um determinado conteúdo ${ }^{2}$. De acordo com Searle (2000b),

1 Como destaca Searle (2000b), o problema da unidade tem sido especialmente estudado pelos neurocientistas contemporâneos em duas linhas de pesquisas: o estudo do problema da integração e o estudo de pacientes com o cérebro seccionado - condição em que o corpo caloso é cortado através de procedimento cirúrgico, separando os dois hemisférios cerebrais, que passam a funcionar de modo autônomo, gerando duas consciências distintas (Gazzaniga \& Heatherton, 2005/2007). Na primeira linha de pesquisa, Searle se debruça sobre o modo como o problema da integração levou alguns neurocientistas, a exemplo de Francis Crick, a supor a existência de correlatos neurais da consciência $(\mathrm{CNC})$. Na segunda, ele cita o trabalho realizado por Michael Gazzaniga e seus colaboradores.

2 É importante esclarecer aqui que não estamos afirmando que os qualia podem ser exaustivamente representados por conteúdos proposicionais, mas que os estados mentais (conscientes ou inconscientes) dotados de intencionalidade (a maioria, na visão searleana) poderiam ser expressos através de conteúdos proposicionais. $\mathrm{O}$ aspecto qualitativo de um estado consciente, contudo, não poderia ser expresso, de maneira exaustiva, como conteúdo proposicional, uma vez que só pode ser vivenciado em primeira pessoa. Em outras palavras, estamos argumentando que a perspectiva de terceira pessoa não dá conta dos qualia. Poder representar não quer dizer que a representação extingue o fenômeno ou captura toda sua força: Quando falo “onça”, não sai onça de minha boca. Essa questão dos qualia tem implicações, por exemplo, na prática da psicanálise, pois uma teoria neurobiológica da consciência deve ser capaz de explicar os estados intencionais. Porém, segundo ele, intencionalidade e estados de consciência nem sempre coincidem. É o caso, por exemplo, de certos estados de ansiedade difusa que parecem ser não-intencionais; ou de crenças que um indivíduo possui mesmo quando se encontra num estado de inconsciência, as quais seriam intencionais, mas deixariam de ser conscientes em determinadas circunstâncias, como durante o sono (Searle, 2000b). Searle também distingue entre intencionalidade intrínseca e intencionalidade como-se (as-if), ou seja, considera que há fenômenos que são de fato intencionais e outros que parecem ser intencionais, mas, na verdade, não o são (Searle, 1992/2006). Nesse sentido, a intencionalidade intrínseca é que seria própria dos estados mentais. Já a intencionalidade como-se poderia ser atribuída a um evento que não é, de fato, intrinsecamente intencional, mas, em certos aspectos, assemelha-se a um evento intrinsecamente intencional, de tal maneira que poderíamos projetar a existência de um estado mental (a partir do comportamento, por exemplo). Para ilustrar a diferença entre os tipos de intencionalidade mencionados, poderíamos dizer que um ser humano, o qual é dotado de estados mentais, possui 'intencionalidade intrínseca', enquanto um computador, que se comporta como se fosse dotado de estados mentais, apenas possui 'intencionalidade como-se'.

No que diz respeito à distinção entre centro e periferia da atenção, podemos dizer que o campo da consciência pode ser alterado na medida em que possuímos a capacidade de dirigir a atenção de um objeto para outro, ou de uma cena para outra, ou de uma sensação táctil para uma percepção visual, por exemplo. De outro modo, mesmo quando focamos nossa atenção em um determinado aspecto da realidade, ainda somos capazes de nos manter conscientes daqueles aspectos que escapam ao centro de nossa atenção. Isso fica claro quando nos remetemos, por exemplo, à ação de dirigir um automóvel: ainda que nossa atenção esteja voltada para uma conversa com o passageiro, para uma música no rádio ou para nossos próprios pensamentos, somos capazes de conduzir o automóvel sem causar acidentes. Contudo, devemos admitir que, em determinadas situações (por exemplo, numa estrada escura, numa pista molhada etc.), é recomendável que nos concentremos mais no foco da atenção.

O estado de humor é outra característica relacionada à consciência. Embora nem sempre precisemos dar nome aos estados de humor que acompanham nossa atividade consciente, os mesmos podem ser vivenciados com maior intensidade e de forma mais evidente em alguns momentos. Assim, eventualmente nos sentimos eufóricos ou deprimidos, por exemplo, sem que isso implique necessariamente um determinado estado de intencionalidade. Podemos dizer, seguindo Searle (1992/2006), que os estados de humor fornecem certa tonalidade às nossas experiências conscientes. Dessa forma, uma pessoa deprimida, por exemplo, não irá viver com a mesma alegria a experiência de passar o réveillon

\footnotetext{
o psicanalista só tem acesso aos significantes expressos no discurso do analisando, e não ao aspecto qualitativo (qualia) da mente deste. Assim, o que é interpretado é o discurso do analisando, por exemplo, sua fala sobre o sonho, e não o sonho em si.
} 
na praia de Copacabana quanto uma pessoa que esteja eufórica. De acordo com Searle, é importante estabelecer uma diferença entre os estados de humor (deprimido, eufórico etc.) e as emoções (medo, raiva etc.): enquanto os primeiros são mais difusos, simples e não-intencionais (como, por exemplo, nas frases: "tenho andado deprimido ultimamente" ou "eu estava eufórico ontem à noite"), as segundas se apresentam com maior clareza, são mais complexas e são dotadas de intencionalidade (como, por exemplo, nas proposições: "tenho medo de cães" ou "tenho raiva de quem joga lixo na rua"). Neste caso, "cães" e "pessoas que jogam lixo no chão" seriam, respectivamente, os objetos, cada um, desses estados.

A dimensão prazer/desprazer é também uma característica presente nos estados de consciência. Podemos dizer, de acordo com Searle (1992/2006, 2000b), que qualquer experiência consciente sempre terá a qualidade de ser prazerosa (proporcionando uma sensação de bem-estar) ou desprazerosa (proporcionando uma sensação de malestar ou desconforto). Searle afirma que, por um lado, a dimensão prazer/desprazer se distingue dos estados de humor, enquanto, por outro, ambos estão relacionados em alguns casos. No entanto, ele não deixa muito claro quais as diferenças entre essas duas características atribuídas aos estados de consciência.

Outra característica que pode ser atribuída a tais estados é a capacidade de organizar, em formas perceptuais coerentes, estímulos perceptivos mais ou menos difusos (Searle, 2000b). Por exemplo, com alguns traços rabiscados em um papel, uma pessoa pode ser capaz de reconhecer a figura de um carro, uma casa etc. Trata-se, portanto, da existência de estruturas gestálticas, tais como explicitadas nos trabalhos de Psicologia da Forma ou Gestalt (Köhler, 1968; Koffka, 1975). Podemos dizer que a capacidade de distinguir entre figura e fundo num determinado campo visual está diretamente relacionada a essas experiências perceptivas que envolvem estruturas gestálticas (Searle, 1992/2006).

Uma última característica dos estados de consciência mencionada por Searle (2000b) é a familiaridade, ou seja, a capacidade que possuímos de reconhecer uma determinada cena ou objeto como sendo algo familiar, já conhecido. Por exemplo, quando passeamos por uma rua de uma cidade que estamos visitando pela primeira vez, observamos casas, árvores e carros que jamais havíamos visto anteriormente. Contudo, somos capazes de reconhecer esses objetos como tendo um aspecto familiar, como algo semelhante a outras casas, árvores e carros que observamos em ruas de quaisquer outras cidades (Searle, 1992/2006). Além disso, somos capazes de estabelecer uma diferença clara entre aqueles objetos (casas, árvores e carros) e os edifícios, os postes e os ônibus, respectivamente. Mesmo numa pintura surrealista de Salvador Dalí (como no caso de A persistência da memória), somos capazes de reconhecer um relógio com aspecto derretido e disforme como sendo um relógio e não outro objeto (Searle, 2000b).

Segundo Searle (2000b), a relação de características estruturais que podemos atribuir aos estados de consciência poderia ser mais extensa. Contudo, para o nosso propósito, é suficiente mencionar apenas as características mais relevantes para uma investigação neurobiológica da consciência.

\section{Investigação Científica da Consciência}

Searle (2010) reconhece que, para realizar um estudo científico da consciência, é necessário seguir alguns procedimentos, que envolveriam três etapas:

Primeiro, descobrir os eventos neurobiológicos correlacionados com a consciência (os NCCs). Segundo, verificar por meio de experimentos se a correlação é uma relação causal autêntica.

$E$, terceiro, tentar desenvolver uma teoria, idealmente na forma de um conjunto de leis, que formalizaria as relações causais. (p. 73)

De acordo com Searle, essas etapas são típicas de qualquer investigação científica, sendo facilmente reconhecidas quando examinamos a história das ciências. Embora reconheçamos que as etapas acima são uma forma válida de fazer ciência, é preciso admitir que há outras visões acerca do modo como se deve realizar uma investigação científica, inclusive no que diz respeito às metodologias utilizadas especificamente no campo das neurociências.

Para Searle (2010), há basicamente dois modos diferentes de realizar uma investigação científica da consciência. O primeiro parte da ideia de que "o campo consciente é constituído de pequenos componentes que se combinam para formá-lo" (Searle, 2010, p. 81). Em outras palavras, o campo da consciência seria dividido em várias partes (a experiência visual, auditiva, motora etc). Assim, se há um correlato neural da consciência $(\mathrm{CNC})$ relativo à experiência visual, também haveria um $\mathrm{CNC}$ relativo às outras modalidades sensoriais. Trata-se da teoria dos blocos de construção (the building block theory). Por sua vez, o segundo modo de realizar um estudo científico da consciência utiliza uma abordagem que a considera como um campo unificado (the unified field theory). Esta abordagem se diferencia da primeira na medida em que, para qualquer modalidade específica vivenciada por um sujeito (a experiência visual, auditiva, motora etc.), esse mesmo sujeito já se apresentaria como alguém consciente desde o princípio, sendo cada experiência vivenciada em sua modalidade apenas uma modificação do campo unificado da consciência.

Searle (2000b) comenta que a teoria dos blocos de construção pode ser encontrada nos trabalhos de Francis Crick (e seus colaboradores). A partir do estudo de fenômenos como a visão cega ${ }^{3}$ e a rivalidade binocular ${ }^{4}$, como também da investigação acerca dos correlatos neurais da visão, os defensores de tal teoria acreditam poder corroborar a hipótese de que o campo da consciência consiste numa ligação de vários estados de consciência, ou micro-consciências. Já a teoria do campo unificado, defendida pelo próprio Searle, incluiria todas aquelas características mencionadas anteriormente (qualidade, subjetividade, unidade etc.), atribuídas aos estados de consciência. Segundo Searle, esta mesma teoria está presente, com algumas variações (às vezes,

3 “A visão cega é uma condição na qual pessoas cegas apresentam algumas capacidades visuais preservadas na ausência de qualquer consciência visual" (Gazzaniga \& Heatherton, 2005/2007, p. 275).

4 Na rivalidade binocular, duas imagens diferentes são apresentadas ao mesmo sujeito e este só consegue enxergar conscientemente uma imagem de cada vez, com um intervalo de poucos segundos entre elas, com a dominância perceptiva entre os dois olhos sendo alternada (Searle, 2000b). 
em combinação com a teoria dos blocos de construção), nos trabalhos de Llinas e seus colegas, bem como de Gerald Edelman e seus colaboradores. Consideremos o caso de Edelman, que sugere a ocorrência da sinalização reentrante ${ }^{5}$ como o mecanismo responsável pela integração entre as diferentes partes do sistema neural, com base em evidências experimentais, por exemplo, sobre o modo unificado e sincronizado como os grupos neuronais de regiões distintas do córtex visual (V1, V2, V3, V4, V5) respondem aos estímulos ambientais durante a percepção (Edelman, 2004; Edelman \& Tononi, 2000). Tais evidências edelmanianas também apoiariam a ideia de que a consciência pudesse ser uma característica neurobiológica de ordem superior, sendo que essa concepção de Edelman, se não coincide, pelo menos se aproxima bastante daquela defendida por Searle (1997/1998, 2000b).

Ao entender a consciência como uma característica biológica do cérebro, Searle (1997/1998, 2000b) oferece uma reflexão sobre as possibilidades de sua investigação pelas neurociências contemporâneas, opondo-se à metáfora da consciência enquanto programa de computador (software) e do cérebro como um computador (hardware). Para Searle, o modelo computacional é inadequado para explicar a consciência ou a mente porque a computação trabalha com propriedades sintáticas que não são intrínsecas à física e que são sempre relativas ao observador, o qual fornece uma descrição dos fenômenos físicos em termos sintáticos (ou seja, em termos da manipulação de símbolos). O erro está em atribuir um caráter intrínseco à sintaxe computacional, transformando uma mera descrição sintática dos fenômenos que ocorrem no mundo físico numa explicação causal desses mesmos fenômenos. Em outras palavras, a sintaxe não possui capacidades causais, tendo em vista que a computação não é, para Searle, algo intrínseco aos fenômenos físicos, mas algo que é atribuído ao mundo físico através de interpretações sintáticas relativas ao observador (Searle, 1992/2006). Ainda de acordo com Searle (1992/2006, 1997/1998, 2002/2010), entre o nível biológico dos eventos neuronais que ocorrem no cérebro e o nível subjetivo e qualitativo dos estados mentais vivenciados em primeira pessoa, não há qualquer nível computacional que apresente um caráter causal e explicativo. O cérebro, segundo ele, opera através de mecanismos biológicos, produzindo a consciência e outros estados mentais sem a necessidade de um programa de computador, ou seja, o cérebro não realiza nenhuma espécie de processamento de informações no sentido puramente sintático ou computacional. Além disso, enquanto um programa de computador é inteiramente definido com base em sua estrutura sintática, os estados mentais são especificamente definidos por apresentarem conteúdos semânticos. A estrutura sintática do programa computacional é puramente formal, não sendo suficiente, na visão de Searle (1984/2000a, 1992/2006), para dar origem à semântica.

\section{O Conceito de Background}

5 Intercâmbio contínuo, recursivo e dinâmico de sinais que ocorre em paralelo entre mapas cerebrais e que continuamente integram esses mapas, uns aos outros, no tempo e no espaço.
Primeiro, lancemos mão da própria definição de Searle (1992/2006) para o que seja tal conceito e sua importância dentro da visão geral de sua obra:

A tese do Background é simplesmente esta: fenômenos intencionais como significados, entendimentos, interpretações, crenças, desejos e experiências só funcionam dentro de um conjunto de capacidades de Background que não são, elas mesmas, intencionais. (p. 250)

Assim, além dos estados mentais conscientes e inconscientes, Searle defende a existência de "capacidades, aptidões e know-how geral que possibilitam que nossos estados mentais atuem" (p. 249), o que ele chama de Background. Portanto, apesar de ser não-intencional, o conjunto de capacidades de Background permite que os estados mentais intencionais ocorram. Outra característica do Background é que esse consiste em "um conjunto de capacidades não-representativas" (Searle, 1992/2006, p. 250), embora seja fundamental para que as representações possam atuar enquanto linguagem, pensamento ou experiência. Em outras palavras, a condição de satisfação de um estado intencional é sempre relativa a um determinado conjunto de capacidades de Background. Como elemento didático e facilitador da compreensão do que sejam essas capacidades, Searle lança mão de um exemplo de Wittgenstein:

Para conceber o Background de uma maneira mais simples, considere o exemplo de Wittgenstein do quadro do homem caminhando para cima. Poderia ser interpretado como um homem deslizando para trás, descendo. Nada de intrínseco ao quadro, mesmo analisado como uma representação pictórica de um homem naquela posição, impõe a interpretação que consideramos natural. A ideia do Background é que o que vale para o quadro vale para a intencionalidade em geral. (p. 252)

Embora um estado intencional, como um desejo ou uma crença, apresente-se sempre relacionado com o Background, há também outra condição de satisfação para que ocorra um estado intencional: a existência de "uma completa Rede de outras crenças e desejos" (Searle, 1992/2006, p. 250). Portanto, a diferença entre Rede e Background é que a primeira é sempre uma rede de estados intencionais ou de representações, enquanto o segundo envolve um conjunto de capacidades não-intencionais e não-representativas. Contudo, em última instância, "a Rede é aquela parte do Background que descrevemos em termos de sua capacidade para causar intencionalidade consciente" (Searle, 1992/2006, p. 269).

\section{Conclusão}

Como afirma Searle (1992/2006), admitir a existência de processos cerebrais que causam a consciência é um passo importante em direção a uma redescoberta da mente. Contudo, à guisa de conclusão, devemos considerar criticamente alguns aspectos da posição assumida por esse filósofo. Em relação à afirmação de que os estados mentais, incluindo a consciência, são causados por microprocessos que ocorrem no cérebro, podemos dizer que, diferentemente de alguns neurocientistas atuais que também trabalham com o problema da consciência, a exemplo de Gerald Edelman (1992/1998, 2004, 2006) e António Damásio (1999/2000, 2010), o filósofo em questão não costuma enfatizar a 
importância do corpo e do ambiente na sua relação com o cérebro como sendo relevantes para a causação dos processos mentais. No entanto, acreditamos que a pouca ênfase dada pelo filósofo a esses fatores não implica necessariamente que os mesmos sejam excluídos de uma discussão acerca do problema da consciência e nem compromete uma possível aproximação da filosofia de Searle das ideias defendidas por alguns neurocientistas contemporâneos, a exemplo daqueles já mencionados. Já no que diz respeito à afirmação de Searle de que os fenômenos mentais são características de nível superior do cérebro, estamos de acordo com alguns críticos do filósofo, como Bennett e Hacker (2008), em sua afirmação de que o argumento de Searle, assim como ocorre com outros filósofos e cientistas, pode ser interpretado como uma falácia mereológica, uma vez que ele acaba por defender a ideia de que o cérebro, como uma parte específica do organismo, possui características ou propriedades que deveriam ser atribuídas ao indivíduo, ou organismo, como um todo. Além disso, Searle não apresenta, como comentamos acima, um modelo claro de emergência, apesar de apelar a esse conceito em seu naturalismo biológico. Por fim, concordamos com Searle quando ele afirma que é necessário encarar de frente o problema mente-corpo tal como construído pela tradição cartesiana (incluindo aqui o materialismo científico). Contudo, a resolução que Searle acredita dar ao problema acaba por introduzir uma espécie de dualismo de perspectivas (perspectiva de primeira pessoa [ontologia irredutível] e perspectiva de terceira pessoa [redução causal]), o que não elimina, de fato, o problema mente-corpo.

Além disso, pode-se alegar que a interpretação de Searle (1992/2006) acerca do dualismo cartesiano perde de vista o fato de que, após Descartes (1641/2004) ter argumentado que mente e corpo são duas substâncias distintas e mutuamente independentes, o filósofo francês busca mostrar que ambos constituem uma "união substancial real", na Meditação Sexta. A distinção entre coisa material e não-material, portanto, é controversa, tendo essa problemática se acirrado após a publicação da obra The concept of mind (Ryle, 1949), na qual Ryle interpreta o cartesianismo como sendo o mesmo que a doutrina do fantasma na máquina. Interpretá-lo assim, no entanto, é praticamente colocar toda a ênfase sobre a primeira e a segunda meditações cartesianas, sendo a sexta meditação quase ignorada. Sem dúvida, há dificuldades importantes na posição de Descartes sobre a relação mentecorpo, mas simplesmente representá-la como um dualismo de substâncias pode obscurecer quais os problemas realmente centrais que ela enfrenta (Muguruza, 2013). Além disso, Descartes (1649/1979) apresenta, em outro escrito, uma discussão neurofisiológica acerca da glândula pineal como "sede" de alma, que indicaria que essa "união substancial real" tratada acima seja para ele, de alguma maneira, natural e inextricável, sendo por ele sustentada com base em um discurso que, ao seu modo e em sua época, tinha pretensões científicas, ainda que hoje esteja completamente superado (Mograbi, Mograbi \& Landeira-Fernandez, 2014). Note-se, contudo, que isso não implica que a discussão do dualismo mente-corpo não seja importante, uma vez que, não obstante as qualificações de que necessitemos na interpretação de tal posição nas meditações de Descartes, a doutrina do fantasma na máquina, de fato, afirmou-se entre os caudatários posteriores do cartesianismo. Daí a relevância da discussão posta por Searle (1992/2006). Reconhecemos, pois, que a posição que Searle apresenta, ainda que não resolva a questão mente-corpo/mente-cérebro, não deixa de ser um avanço importante na tentativa de enfrentar a tradição cartesiana, uma vez que tem o mérito de introduzir um novo desafio para aqueles que se ocupam do problema mente-corpo/mente-cérebro, um desafio que parece fazer sentido no atual cenário científico. $\mathrm{O}$ desafio consiste em partir de uma ontologia já não mais cartesiana, tendo em vista que a ciência (e, em particular, o conhecimento científico acerca do funcionamento do cérebro) avançou consideravelmente desde o século XVII. Nesse cenário, é evidente que o dualismo de substâncias não é mais viável como ponto de partida filosófico (ao menos para aqueles que consideram ser necessário a filosofia dialogar com a ciência contemporânea). Entendemos que essa seja uma das principais contribuições de Searle para o debate acerca da consciência na atualidade. Contudo, não obstante as recorrentes tentativas de Searle de recusar o dualismo de propriedades, essa posição ainda persiste na filosofia da mente atual (Churchland, 1997; Maslin, 2007/2009). Se, para esse filósofo, a consciência é inapelavelmente irredutível no nível ontológico, porque a subjetividade é a propriedade fundamental da ontologia de primeira pessoa, mas, ao mesmo tempo é redutível em termos causais, como propriedade biológica, fica claro que Searle acaba por abraçar um dualismo de propriedades. Enfim, podemos dizer que, se a posição defendida por Searle de fato não resolve o problema mente-corpo, certamente acaba por reintroduzí-lo a partir de uma nova formulação menos viciada pelas pressuposições metafísicas.

\section{Referências}

Araújo, S.F. (2010). O projeto de uma psicologia cientifica em Wilhelm Wundt: uma nova interpretação. Juiz de Fora: Ed. UFJF.

Bennett, M. R., \& Hacker, P.M.S. (2008). Philosophical Foundations of Neuroscience. Oxford: Blackwell Publishing.

Churchland, P. S. (1997). Can neurobiology teach us anything about consciousness? In N. Block, O. Flanagan \& G. Güzeldere (Eds.), The Nature of Consciousness (pp. 127140). Cambridge: MIT Press.

Crick, F. (1994). The Astonishing Hypothesis: The Scientific Search for the Soul. New York: Charles Scribner's Sons.

Damásio, A. R. (2000). O mistério da consciência (L. T. Motta, trans.). São Paulo: Companhia das Letras. (Trabalho original publicado em 1999)

Damásio, A. R. (2010). Self comes to mind: constructing the conscious brain. New York: Pantheon Books.

Descartes, R. (1979). As Paixões da Alma (J. Guinsburg \& B. Prado Jr., trans.), 2a ed., pp. 213-294, Coleção Os Pensadores). São Paulo: Editora Abril. (Trabalho original publicado em 1649)

Descartes, R. (2004). Meditações sobre Filosofia Primeira (F. Castilho, trans.). Campinas: Editora Unicamp. (Trabalho original publicado em 1641) 
Edelman, G. M. (1998). Biologia da consciência (J. D. Nogueira, trans.). Lisboa: Instituto Piaget. (Trabalho original publicado em 1992)

Edelman, G. M. (2004). Wider than the sky: the phenomenal gift of consciousness. New Haven and London: Yale University Press.

Edelman, G. M. (2006). Second Nature: Brain science and human nature. New Haven and London: Yale University Press.

Edelman, G. M., \& Tononi, G. (2000). A Universe of Consciousness: How matter becomes imagination. New York: Basic Books.

Freud, S. (1990). "Projeto para uma psicologia científica". In: Freud, S. (1990). Edição standard brasileira das obras psicológicas completas de Sigmund Freud. v. 1, p. 385-529. Rio de Janeiro: Imago. (Trabalho original publicado em 1950 [1895]).

Freud, S. (1990). "Esboço de Psicanálise". In: Freud, S. (1990). Edição standard brasileira das obras psicológicas completas de Sigmund Freud. vol. 23. Rio de Janeiro: Imago. (Trabalho original publicado em 1940 [1938]).

Freud, S. (2001). A Interpretação de Sonhos. (W. I. Oliveira, trans.) Rio de Janeiro: Imago. (Trabalho original publicado em 1900).

Freud, S. (2006). "O Inconsciente". In: Freud, S. (2006). Escritos sobre a psicologia do inconsciente. Vol. 2, p. 13-74. Rio de Janeiro: Imago. (Trabalho original publicado em 1915).

Gazzaniga, M. S., \& Heatherton, T. F. (2007). Ciência Psicológica: Mente, cérebro e comportamento (M. A. V. Veronese, trans.). Porto Alegre: Artmed. (Trabalho original publicado em 2005)

James, W. (2010). The principles of psychology, vol. 1. Digireads. com Publishing. (Trabalho original publicado em 1890).

Koffka, W. (1975). Princípios da Psicologia da Gestalt. São Paulo: Cultrix.

Köhler, W. (1968). Psicologia da Gestalt. Belo Horizonte: Itatiaia.
Maslin, K.T. (2009). Introdução à filosofía da mente (F. J. R. da Rocha, trans.). Porto Alegre: Artmed. (Trabalho original publicado em 2007)

Mograbi, D. C., Mograbi, G. J. C., \& Landeira-Fernandez, J. (2014). Aspectos históricos da neuropsicologia e o problema mentecérebro. In D. Fuentes, L. Malloy-Diniz, C. D. P. de Camargo \& R. M. Consenza (Eds.), Neuropsicologia: Teoria e prática (pp. 19-27). Porto Alegre: Artmed.

Muguruza. M. (2013). Mente, ciência e consciência em John Searle. (doctoral dissertation), Programa de Pós-Graduação em Ensino, Filosofia e História das Ciências, Universidade Federal da Bahia, Salvador.

Ryle, G. (1949). The concept of mind. New York: Barnes \& Noble.

Searle, J. R. (1998). O mistério da consciência (A. Y. P. Uema \& V. Safatle, trans.). São Paulo: Paz e Terra. (Trabalho original publicado em 1997)

Searle, J. R. (2000a). Mente, cérebro e ciência (A. Morão, trans.). Lisboa: Edições 70. (Trabalho original publicado em 1984)

Searle, J. R. (2000b). Consciousness. Annual Review of Neuroscience, 23, 557-578.

Searle, J. R. (2006). A redescoberta da mente (E. P. e Ferreira, trans.). São Paulo: Martins Fontes. (Trabalho original publicado em 1992)

Searle, J. R. (2007). Liberdade e neurobiologia: Reflexões sobre o livre-arbitrio, a linguagem e o poder politico (C. M. E. Morel, trans.). São Paulo: Editora UNESP. (Trabalho original publicado em 2004)

Searle, J. R. (2010). Consciência e linguagem (P. J. Smith, trans.). São Paulo: Martins Fontes. (Trabalho original publicado em 2002) 